\title{
TRAUMATISMOS DEL HUESO TEMPORAL
}

\author{
Drs. Guido González $T^{(1,2)}$, Máximo Mújica $B^{(1)}$, Cristián Larraín $G^{(1)}$, Patricio Miller $T^{(1)}$.
}

1. Servicio TAC y RM, Departamento de Imágenes, Clínica Alemana de Santiago.

2. Servicio de Radiología Hospital San Juan de Dios.

\begin{abstract}
Injuries to the temporal bone are caused by high energy mechanisms. Fractures, longitudinal or transverse, are the most frequent lesions and they need to be specifically searched. If the fracture is not visible, its presence is suspected by means of indirect signs, such as soft tissue occupation within mastoid cells, or in the tympanic cavity, and air in an abnormal situation. The ossicular chain can undergo luxations, being the most frequent the incudomallear joint, and fractures.
\end{abstract}

For the study of traumatic injuries of the temporal bone, the CT scan should be the method of choice, especially by means of multislice technology, since the speed of acquisition, and the good quality of multiplanar reconstructions, facilitates the diagnosis.

Key words: temporal bone, Traumatic injury

Resumen: Los traumatismos del hueso temporal ocurren por mecanismos de alta energía. Las fracturas, longitudinales o transversales, son las lesiones más frecuentes y deben buscarse dirigidamente. Si el rasgo de fractura no es visualizado, signos indirectos como ocupación de partes blandas en celdillas mastoideas o en la caja timpánica y aire en lugares no habituales, deberían aumentar la sospecha. La cadena de huesecillos puede lesionarse por luxaciones, la incudomaleolar es la más frecuente, 0 por fracturas.

Para el estudio de las lesiones traumáticas del hueso temporal, la tomografía computada debe ser el método de elección, sobretodo si se realiza con tecnología multicorte ya que, la rapidez en la adquisición y la gran calidad en reconstrucciones multiplanares facilita el diagnóstico.

Palabras claves: Hueso temporal, Trauma.

González G, y col. Traumatismos del hueso temporal. Rev Chil Radiol 2002; 8: 177-181.

Correspondencia: Dr. Guido González T.
El hueso temporal frecuentemente resulta dañado en los traumatismos que afectan al cráneo. Sin embargo, ello también puede ocurrir como consecuencia de impactos directos (Figura 1), cuerpos extraños o heridas penetrantes ${ }^{(1)}$. Cuando estamos en presencia de una fractura de hueso temporal ha habido de por medio un traumatismo de alta energía, por lo que la asociación con otras fracturas de cráneo y lesiones intracraneales es frecuente.

La exploración radiológica del hueso temporal en un traumatismo debe realizarse en el contexto adecuado. Si se está en presencia de un paciente politraumatizado, con lesiones importantes de cabeza y cuello, la evaluación y manejo de éstas debe primar por sobre el estudio dirigido del oído.

En las situaciones de urgencia, ante la evidencia o sospecha clínica de lesión de hueso temporal el examen de elección es la tomografía computarizada (TC), la que debe incluir sólo cortes axiales, difiriendo los coronales hasta que las condiciones del paciente lo permitan. La TC realizada en forma diferida debe incluir cortes axiales y coronales, el grosor de corte ideal debería ser de 1,0 mm con algoritmo óseo y sin uso de contraste. En la actualidad, con la nueva generación de TC multicorte, el estudio se simplifica ya que la adquisición se realiza sólo en el plano axial con un grosor de corte de 0,5 $\mathrm{mm}$ obteniendo posteriormente reconstrucciones multiplanares de óptima calidad (Figura 2).

Cualquiera sea la modalidad de estudio se debe ir dirigidamente a analizar ${ }^{(2)}$ :

1. Los bordes del peñasco: en busca de soluciones de continuidad.

2. Origen de los rasgos de fractura: occipital o temporal.

3. El recorrido entero del nervio facial: sobre todo si no se ha demostrado fractura.

4. La cadena de huesecillos: revisando su integridad.

5. Opacificación de celdillas mastoideas: ya que orienta hacia la existencia de fracturas. 

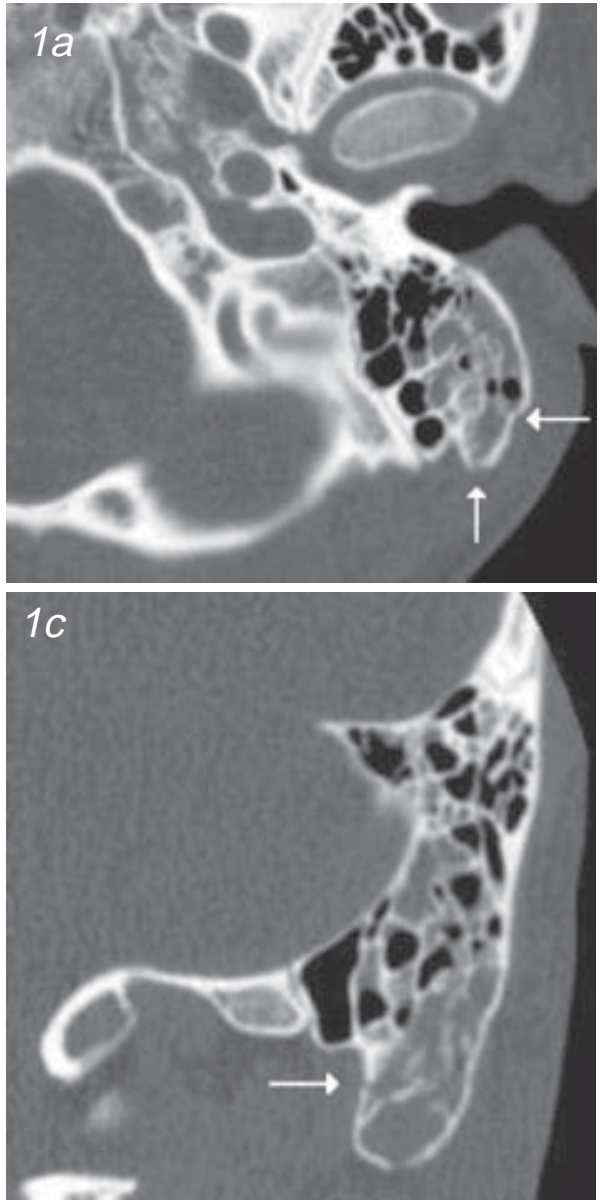
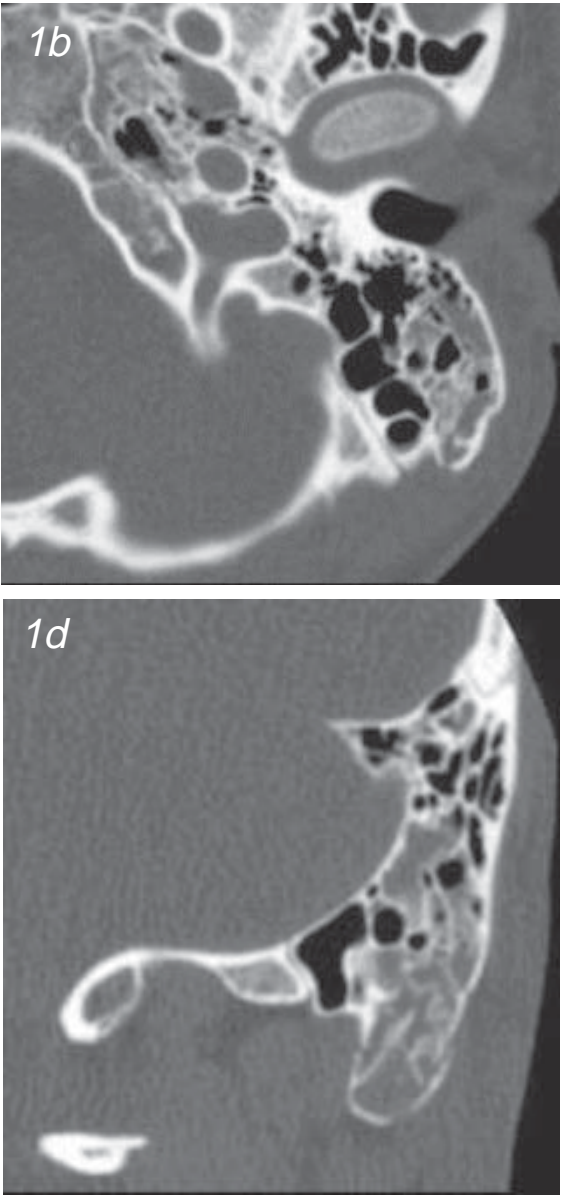

Figura 1a, b, c, d. Fractura por impacto directo. Hombre de 19 años, jugando fútbol recibe codazo retroauricular izquierdo. (a) y (b): Cortes axiales, ocupación hemática distal del proceso mastoideo izquierdo. Se identifican dos finos rasgos de fractura posterolaterales (flechas en a). (c) y (d):cortes coronales identifican fractura del vértice y pared medial de la mastoides (flecha en $\mathrm{c}$ ).

6. Aire en lugares no habituales: sobre todo en las vecindades del peñasco, por ejemplo, aire en la articulación temporo madibular es un signo muy sugerente de fractura(3).

\section{Fracturas del peñasco}

A. Clasificación ${ }^{(1,2,4,5)}$ :

A1. Longitudinales: siguen el eje mayor del peñasco, son las más frecuentes con alrededor del $85 \%$ del total y están asociadas a traumatismos témporoparietales. Habitualmente comprometen el oído medio hasta el techo del conducto auditivo externo y pueden provocar pérdida de la audición de tipo conductiva y fístulas del líquido cefalorraquídeo (Figura 3).

A2. Transversales: son perpendiculares al eje mayor del peñasco y generalmente asociadas a traumatismos occipitales. Afectan el oído interno y pueden provocar pérdida de la audición de tipo neurosensorial y vértigo por compromiso de las ramas coclear y vestibular del VIII par craneano respectivamente (Figura 4).

A3. Mixtas.

\section{B. Complicaciones:}

B1. Pérdida de la audición: Es junto con el daño del nervio facial, la complicación más frecuente. En Tabla I se muestra la clasificación y sus causas.

B2. Daño del nervio facial: ya sea por laceración o por compresión de él secundario a edema o a hematoma. El compromiso del VII par puede verse tanto en las fracturas longitudinales -donde se daña en la porción timpánica inmediatamente después del ganglio geniculado- como en las fracturas transversales en su porción laberíntica justo antes del ganglio

Tabla I. Causas de pérdida de la audición en traumatismos de hueso temporal

\begin{tabular}{ll}
\hline Conductiva & $\begin{array}{l}\text { Rotura timpánica: más frecuente } \\
\text { Hemotímpano } \\
\text { Daño en cadena de huesecillos }\end{array}$ \\
Neurosensorial & $\begin{array}{l}\text { Daño coclear } \\
\text { Daño en VIII par }\end{array}$
\end{tabular}



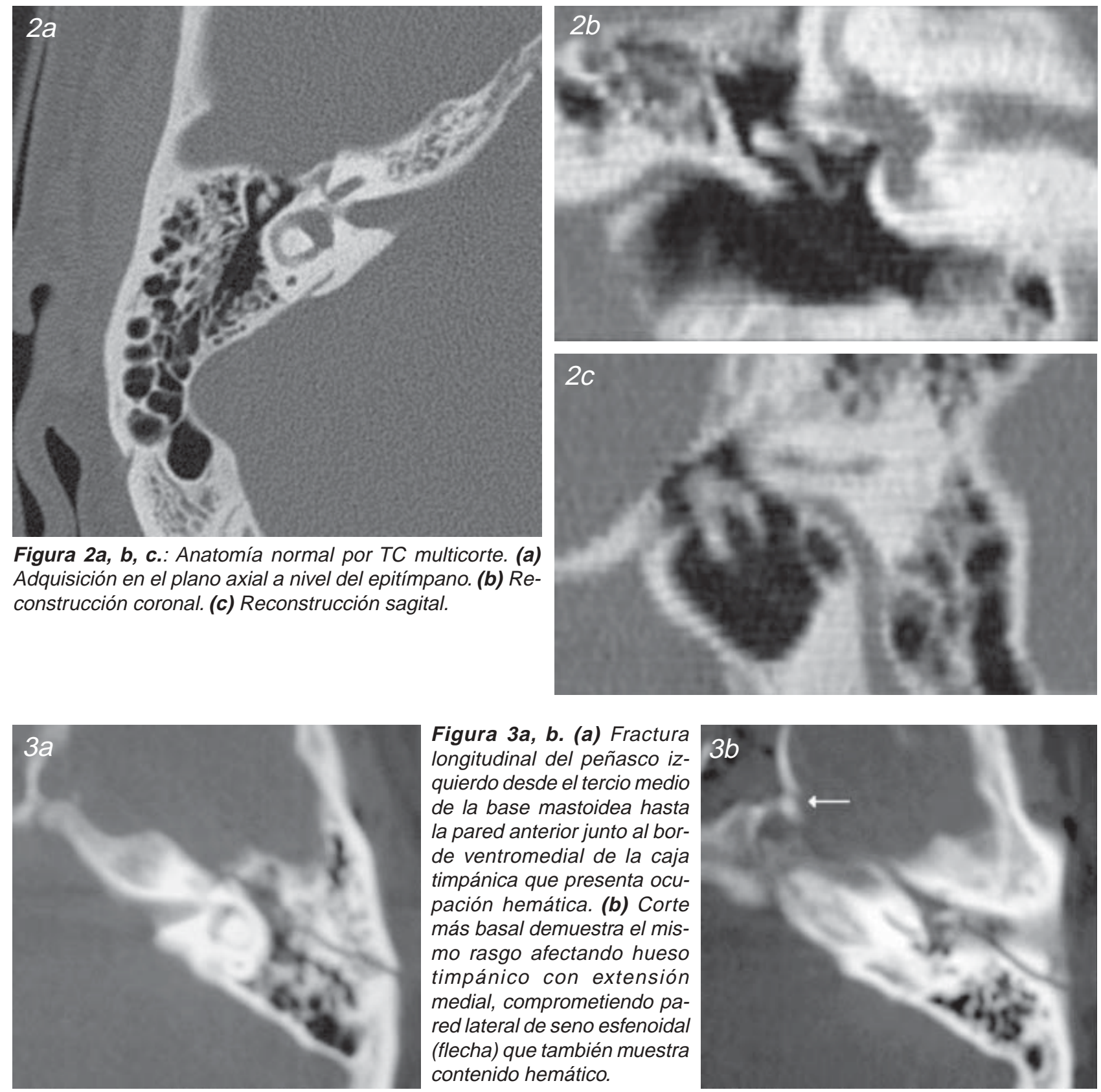

Figura 3a, b. (a) Fractura longitudinal del peñasco izquierdo desde el tercio medio de la base mastoidea hasta la pared anterior junto al borde ventromedial de la caja timpánica que presenta ocupación hemática. (b) Corte más basal demuestra el mismo rasgo afectando hueso timpánico con extensión medial, comprometiendo pared lateral de seno esfenoidal (flecha) que también muestra contenido hemático.
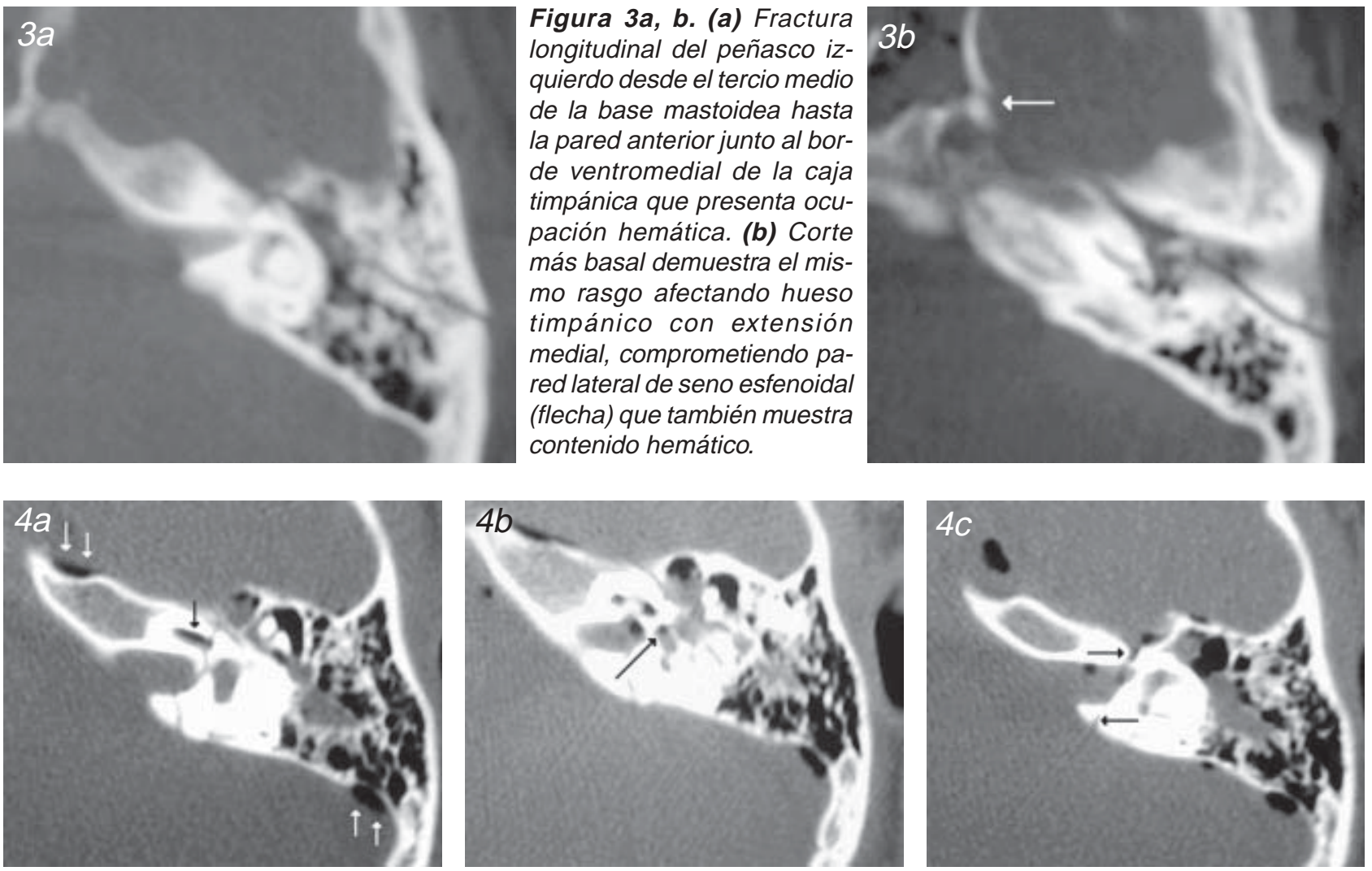

Figura 4a, b, c. Niño de 7 años. Cae desde una reja. Evoluciona con pérdida de la audición y paresia facial izquierda. (a) Fractura transversal del peñasco izquierdo con compromiso del fondo del conducto auditivo interno, neumolaberinto en el interior de la espira basal de la cóclea (flecha negra) y neumoencéfalo (flechas blancas). Ocupación hemática de epitímpano y antro mastoideo. (b) Aire en el interior del vestíbulo (flecha). (c) El rasgo de fractura se extiende a través de la porción laberíntica del nervio facial (flechas). 
geniculado. En ambos casos se manifiesta como parálisis o paresia, por lo que urge diagnosticar el lugar de la lesión para orientar la cirugía de reparación o descompresión.

B3. Fístulas de LCR: habitualmente ocurren hacia la caja timpánica por fractura del tegmen timpani y laceración meníngea. También puede fistulizarse hacia la mastoides. Para que se produzca otorrea de LCR se requiere tener asociada una perforación del tímpano, ya que, si no existe, el LCR fluirá por la trompa de Eustaquio hacia la nasofaringe y de allí a las fosas nasales, manifestándose como rinorrea.

B4. Colesteatoma: la formación de un colesteatoma de tipo adquirido puede ocurrir si restos de epitelio epidérmico invaden el foco de fractura previo a la formación de callo óseo ${ }^{(5)}$.

B5. Compromiso del canal carotídeo: que puede provocar compresión arterial con oclusión secundaria.

\section{Daño en la cadena de huesecillos}

Puede ocurrir por una contusión cerrada, por fracturas de cráneo, por heridas penetrantes o cuerpos extraños en el oído medio. Aproximadamente un
$30 \%$ de las fracturas de hueso temporal se asocian a compromiso de los huesecillos. En el estudio del traumatismo de la cadena osicular el examen de elección también es la TC, siendo lo más importante el acabado conocimiento de su anatomía normal, tanto en el plano axial como en el coronal y, en caso de duda, la utilización de reconstrucciones en otros pla$\operatorname{nos}^{(6)}$.

El daño osicular puede ser de dos tipos: luxación o fractura. Lo más frecuente son las luxaciones $(90 \%)$ y entre ellas las más habituales son las que afectan a la articulación incudoestapedial, entre el yunque y el estribo (Figura 5), seguida por la incudomaleolar, entre el yunque y el martillo (Figura 6). Esto se debe a que el yunque presenta una precaria suspensión respecto a los otros huesecillos, sin inserciones musculares propias y con un débil soporte ligamentoso. Por el contrario, el martillo está fijo firmemente a la membrana timpánica, y el estribo a la ventana oval, lo que, junto a las inserciones musculares propias que poseen, les confieren mayor estabilidad frente a traumatismos.

Las fracturas osiculares (10\%) pueden afectar
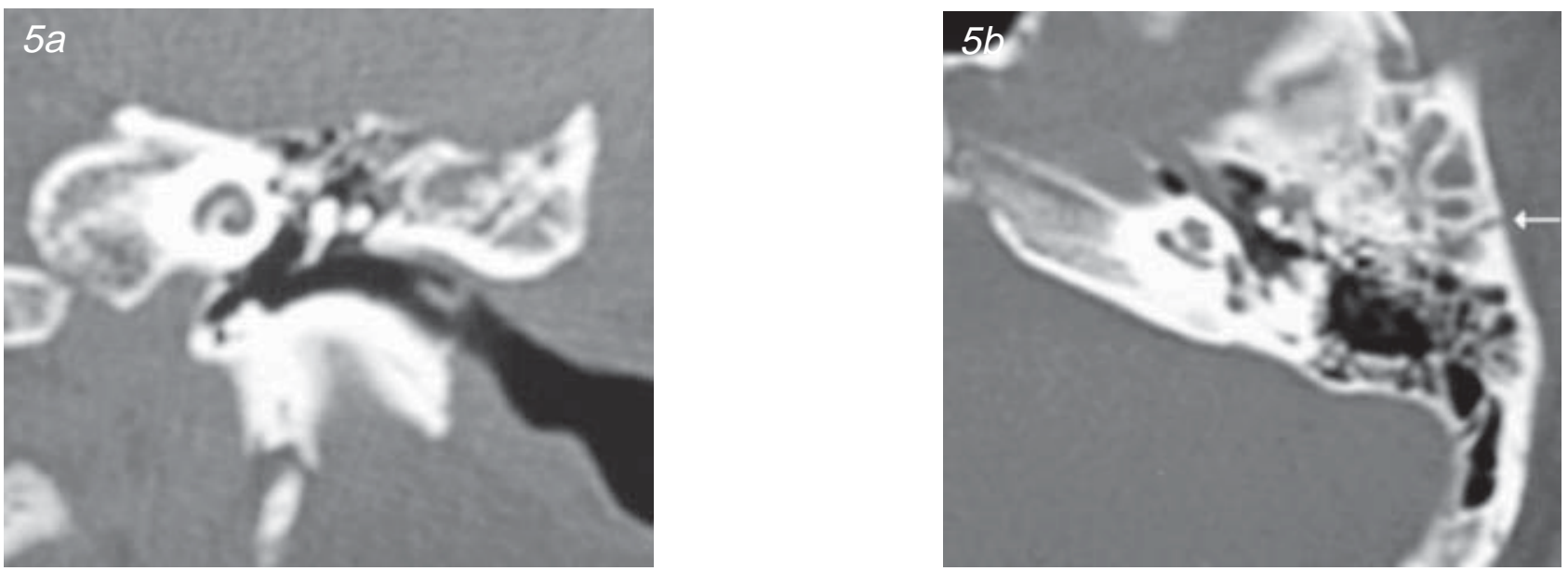

Figura 5a, b. Luxación incudo-estapedial. Niña de 14 años, cae desde el camarote con impacto mandibular. Evoluciona con hipoacusia derecha.(a) Corte axial demostrando separación entre yunque y estribo (flecha) con leve rotación del yunque. Compárese respecto del lado izquierdo normal en (b).

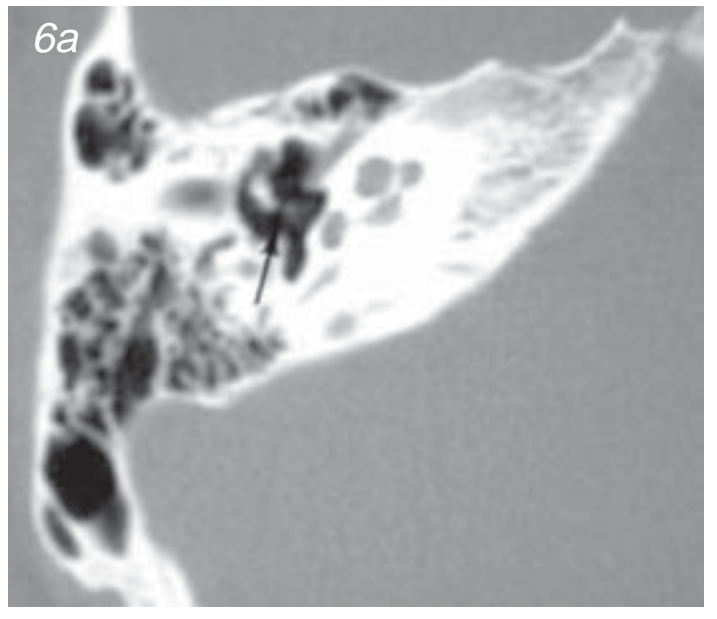

Figura 6a, b. Luxación incudo-maleolar. (a) Corte coronal muestra diástasis entre martillo y yunque con posición más lateral y basal del martillo. (b) Corte axial. Nótese fractura mastoidea en el plano coronal (flecha).

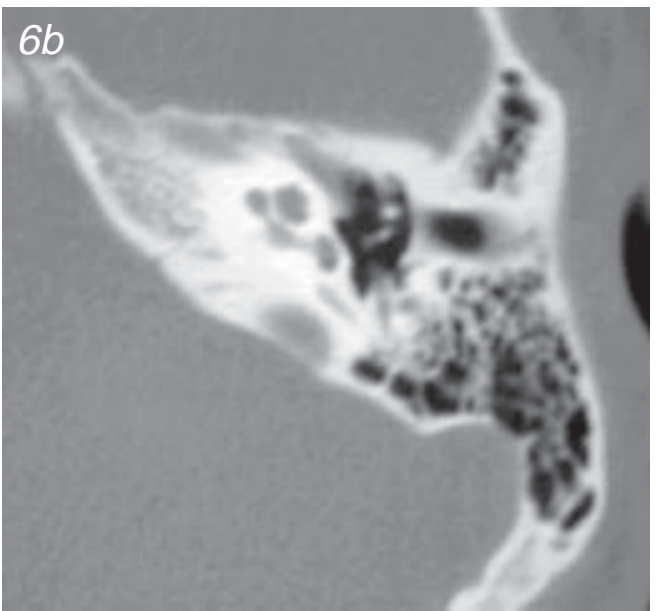




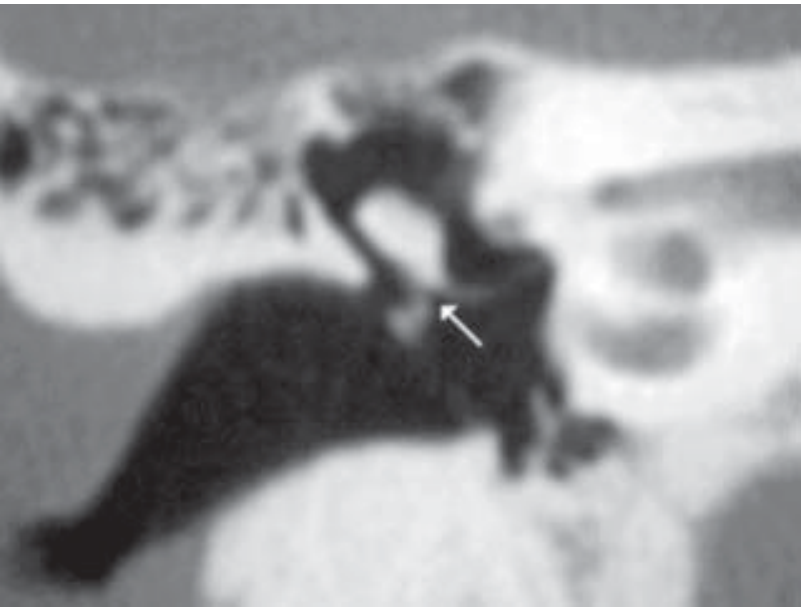

Figura 7. Fractura del martillo a nivel del cuello (flecha).

al martillo, generalmente, en el cuello o en el manubrio (Figura 7), al yunque en la apófisis larga y al estribo en el arco o en la base.

\section{Conclusión}

En presencia de traumatismos cráneoencefálicos de alta energía, se debe sospechar y bus- car específicamente lesiones en el hueso temporal. El estudio de estas eventuales lesiones debe realizarse con tomografía computada dirigida. Para ello, es necesario tener un acabado conocimiento de la anatomía local y de las lesiones y complicaciones traumáticas que afectan al peñasco y su contenido.

\section{Bibliografía}

1. Gean AD. Temporal Bone Trauma en Gean AD: Imaging of Head and Neck Trauma, 56-71. New York 1994, Raven Press.

2. Harnsberger HR. The Temporal Bone: External, Middle and Inner Ear Segments. En Harnsberger HR: Handbook of Head and Neck Imaging, Cap. 17: 455456. St. Louis, 1995, Mosby-Year Book.

3. Betz BW, Wiener MD. Air in the temporomandibular joint fossa: CT sign of temporal bone fracture. Radiology, 1991;180: 463-466.

4. Johnson DW, Hasso AN, Stewart CE, et al. Temporal Bone Trauma: HRCT Evaluation. Radiology 1984;151: 411-415.

5. Swartz JD. Temporal Bone Trauma en Som PM and Curtin HD: Head and Neck Imaging, Cap. 30: 14251431. St. Louis, 1996, Mosby-Year Book.

6. Meriot P, Veillon F, Garcia JF, et al. CT Appearences of Osicular Injuries. RadioGraphics 1997;17: 1445-1454. 